\title{
The role of superalloy precipitates on the early stages of oxidation and type II hot corrosion
}

\author{
A. Potter, J. Sumner, N. J. Simms \\ Cranfield University, Cranfield, Bedfordshire, MK43 OAL, UK. \\ (j.sumner@,cranfield.ac.uk)
}

\begin{abstract}
To meet materials challenges encountered in gas turbines superalloys have been developed for high temperature, strength, oxidation and corrosion resistance. One strengthening method is using refractory metal additions to form carbide precipitates. However, such precipitates may be detrimental to the alloy's environmental resistance. This paper reports how refractory metal carbide precipitates affect the early stages of oxidation and hot corrosion of two alloys: Rene 80 (nickel-based) and MarM 509 (cobalt-based). Samples were exposed at $700{ }^{\circ} \mathrm{C}$ in either dry synthetic air or $90 \mathrm{ppm}$ $\mathrm{SO}_{\mathrm{x}}, 10.5 \% \mathrm{CO}_{2}, 8.5 \% \mathrm{O}_{2}, 5 \% \mathrm{H}_{2} \mathrm{O}\left(\right.$ balance $\left.\mathrm{N}_{2}\right)$ with a $80 / 20(\mathrm{Na} / \mathrm{K})_{2} \mathrm{SO}_{4}$ deposit $\left(1.5 \mu \mathrm{g} / \mathrm{cm}^{2} /\right.$ hour flux $)$.

The oxidation morphology and corrosion products were investigated by scanning electron microscope and energy dispersive $\mathrm{X}$-ray analysis, to show that refractory metal carbide precipitates close to the metal surfaces disrupt protective oxide scale formation, thus providing inward transport routes for corrosive species.
\end{abstract}

Keywords: oxidation; hot corrosion; superalloys; MarM 509; Rene 80

\section{Introduction}

Critical components within gas turbines, such as blades, vanes and discs, operate under a combination of high temperatures, mechanical stresses and chemical attack [1]. Nickel and cobalt-based superalloys have been developed to withstand such conditions for extended periods [2]. However, compositional and microstructure changes intended to 
improve to one aspect of alloy performance (e.g. strength) may detrimentally affect other aspects (e.g. environmental resistance). For example, one method to enhance the strength of superalloys is the addition of refractory metal carbide phases [3], but some studies have indicated that these precipitate phases may be detrimental to the alloy's environmental resistance $[4,5]$.

In addition to the mechanical challenges facing gas turbine components, chemical attack can also take place [6]. Oxidation can occur throughout the surface temperature range of interest (from $\sim 600$ to $1000{ }^{\circ} \mathrm{C}$ ), but with rates increasing with temperature [7]. However, hot corrosion can occur via different mechanisms that vary with temperature, but which all involve the presence of molten salt deposits [8]. Hot corrosion is broadly divided into two categories: type I (broad front attack with internal damage) and type II (often appearing as localised pitting) occurring at approximately 900 and $700{ }^{\circ} \mathrm{C}$ respectively [9]. Both hot corrosion phenomena have been observed to occur in two stages: an incubation stage that corresponds to the breakdown of the surface's protective oxide scale, followed by a propagation stage where corrosive species can access the unprotected metal and more rapid metal damage can occur [10]. If hot corrosion is life-limiting, then the incubation stage can be a significant proportion of the lifetime of a component and therefore factors that influence this stage are of particular interest [11].

This paper reports the effects that alloy refractory carbide precipitates have on the development of protective oxides and the incubation stage of type II hot corrosion using example nickel and cobalt-based alloys. To understand the roles corrosive species play in the degradation sequence, exposures were carried out in both oxidising and type II hot corrosion conditions. 


\section{Experimental methodology}

Oxidation and type II hot corrosion exposures were carried out using two example alloys: nickel-based Rene 80 and cobalt-based MarM 509 (compositions given in Table 1). Both types of exposure were carried out in a ceramic-lined, controlled atmosphere furnace (Figure 1) with the two gaseous environments generated using different input gas bottles.

The superalloy samples were solid cylinders with diameters and heights of approximately $10 \mathrm{~mm}$ which were freshly prepared to give an average surface roughness $\left(R_{a}\right)$ of $\leq 0.4 \mu \mathrm{m}$.

The oxidation tests were carried out for 100 hours at $700{ }^{\circ} \mathrm{C}$ in a dry synthetic air environment supplied from a certified gas bottle at $50 \mathrm{~cm}^{3} /$ minute. The type II corrosion tests were carried out for up to 500 hours using the "deposit re-coat" test methodology [12]. An 80/20 molar ratio $\mathrm{Na}_{2} \mathrm{SO}_{4} / \mathrm{K}_{2} \mathrm{SO}_{4}$ deposit was used at a flux of $1.5 \mu \mathrm{g} / \mathrm{cm}^{2} / \mathrm{h}$. This deposit was applied cyclically every 100 hours. The inlet gas composition was 90 ppm $\mathrm{SO}_{2}, 8.5 \% \mathrm{O}_{2}, 10.5 \% \mathrm{CO}_{2}, 5 \% \mathrm{H}_{2} \mathrm{O}$ (vol.\%) and balance $\mathrm{N}_{2}$ (simulating the hot gas pathway of an industrial gas turbine under one example operating condition [5]).

Table 1: Nominal alloy compositions in Wt.\%

\begin{tabular}{llllllllllll}
\hline Alloy & Ni & Co & Cr & Ti & W & Al & Ta & Mo & C & B & Zr \\
\hline MarM 509 & 10 & Bal & 23.5 & 0.2 & 7 & - & 3.5 & - & 0.6 & - & 0.5 \\
Rene 80 & Bal & 9.5 & 14 & 5 & 4 & 3 & - & 4 & 0.16 & 0.015 & 0.03 \\
\hline
\end{tabular}




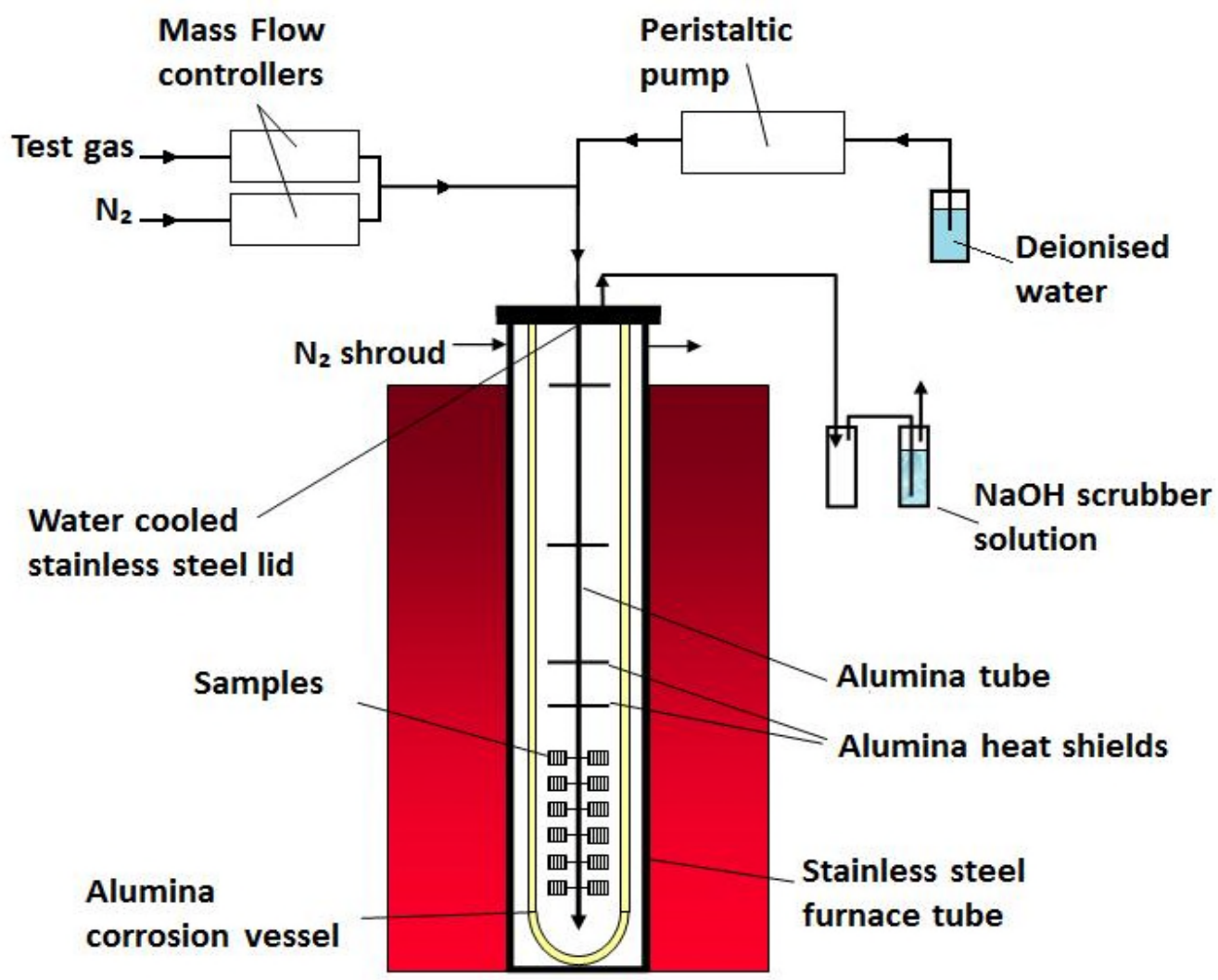

Figure 1: Schematic of the test furnace set up for operation with corrosive gases.

Post-exposure, cross-sections of the specimens were mounted in a low shrinkage cold setting resin mixed with $\sim 50 \%$ ballotini (to further reduce resin shrinkage) and then ground/polished to a $1 \mu \mathrm{m}$ finish using non-aqueous lubricants. The changes in surface damage morphology were investigated through micrographs and element maps produced using a Philips XL30 environmental scanning electron microscope (ESEM) equipped with an Oxford Instruments energy dispersive X-ray (EDX) analysis system.

\section{Results and discussion}

Figure 2 shows backscattered electron images (BSI) of the larger phases present in both MarM 509 and Rene 80, with the associated EDX analyses being given in Table 2. MarM 509 exhibits two main carbide precipitate phases: one rich in tantalum (lighter shade) and one rich in chromium (darker shade). These two phases are of irregular 
shape and exist as part of a structure of precipitates throughout the alloy matrix.

Rene 80 also has two identifiable carbide phases, in addition to the main $\gamma / \gamma^{\prime}$ phase mixture. These carbide phases are of variable size with the larger phase (approximately 10-100 $\mu \mathrm{m}$ ) irregularly shaped and rich in titanium and tungsten, while a smaller phase (up to approximately $2 \mu \mathrm{m}$ ) is rich in molybdenum. The larger precipitates have similar backscattered electron contrast to the substrate, while the smaller ones appear lighter indicating a greater concentration of heavier elements.

Another study in the literature has also identified additional smaller MC carbide phases precipitated along crystallographic planes of the alloy matrix [13]. These have not been observed in this present study, possibly due to the limitations of the ESEM.
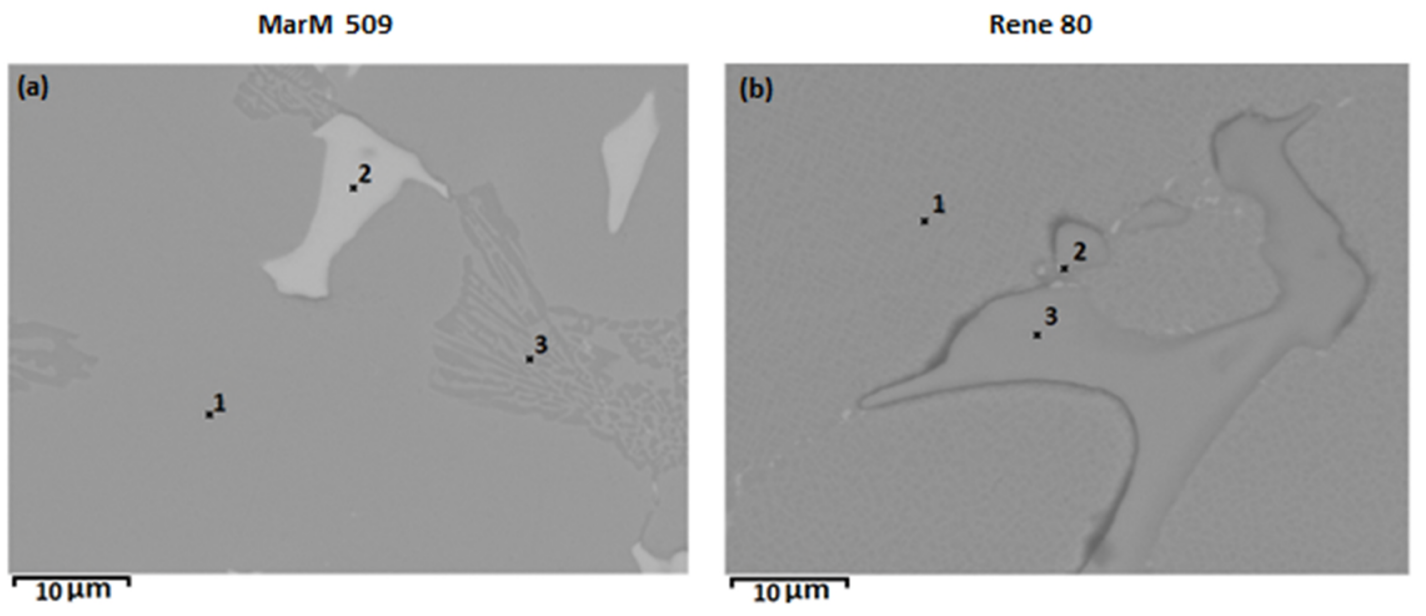

Figure 2: BSI of selected points showing the larger carbide phases present in (a) MarM 509 and (b) Rene 80

Table 2: Element compositions (Wt.\%) of selected points in Figure 2 for MarM 509 and Rene 80.

(a) MarM 509

\begin{tabular}{cccccccc}
\hline & Co & $\mathbf{N i}$ & $\mathbf{C r}$ & $\mathbf{T a}$ & $\mathbf{T i}$ & $\mathbf{W}$ & $\mathbf{Z r}$ \\
\hline Point 1 & 52.1 & 9.8 & 23.9 & 4.7 & 0.2 & 9 & 0.4 \\
Point 2 & 27.8 & 5.4 & 13.8 & 38.3 & 2.4 & 7.9 & 4.3 \\
Point 3 & 41.6 & 7.8 & 34.7 & 5.2 & 0.2 & 9.9 & 0.5
\end{tabular}

(b) Rene 80

\begin{tabular}{cccccccc}
\hline & Co & Ni & Cr & Mo & Ti & W & Fe \\
\hline Point 1 & 9 & 58.4 & 13.3 & 4.1 & 6.3 & 5.1 & 0.7 \\
Point 2 & 6.4 & 39.3 & 14.2 & 17.2 & 8.4 & 11.9 & 0.7 \\
Point 3 & 4.9 & 30.1 & 7.9 & 10.2 & 27.2 & 17.5 & 0.9
\end{tabular}


Figure 3 shows the BSI and associated EDX elemental maps for MarM 509 after exposure at $700{ }^{\circ} \mathrm{C}$ in air for 100 hours. Two large precipitate phases are shown in contact with the sample's surface while a third (to the left of these) may also contact the surface out of the imaging plane. From the EDX maps it is apparent that these precipitates are undergoing a change in chemistry moving inward from the surface with a disrupted region near the surface and protruding outwards.

The oxygen map shows that the metal carbide precipitates at the alloy surface have oxidized approximately $20 \mu \mathrm{m}$ inwardly along the precipitate. This oxidation is associated with the diffusion of specific elements to the metal surface and formation of metal oxides at the surface. These changes have created an area of the surface that is devoid of a protective oxide scale and would therefore be vulnerable to further environmental attack. Additionally, the boundary between the oxidized precipitate and the main alloy matrix appears well defined and may provide an inward transport route for oxygen that may allow lateral oxidation of the bulk alloy.

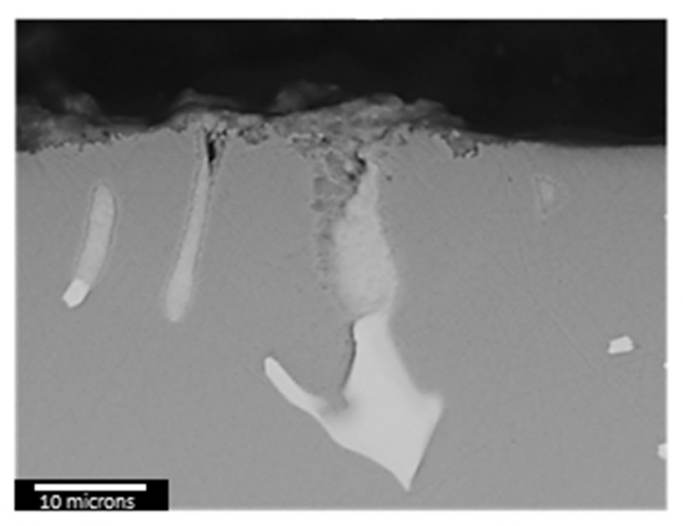

Co

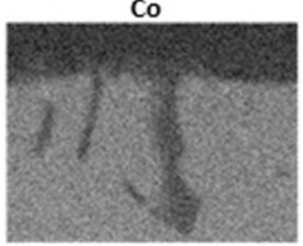

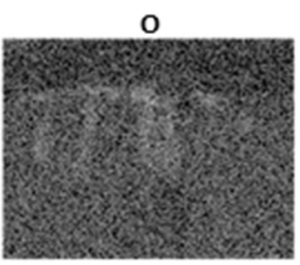

$\mathrm{Ti}$

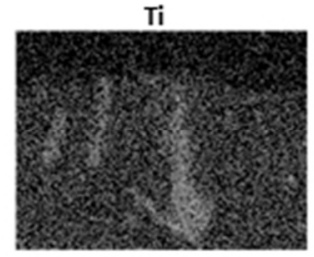

Ta

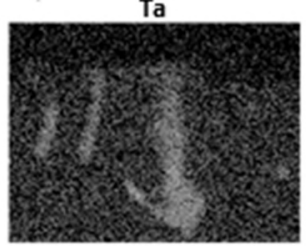

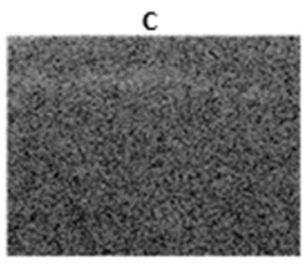

$\mathrm{Cr}$

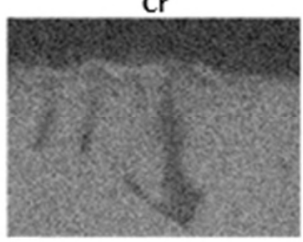

w

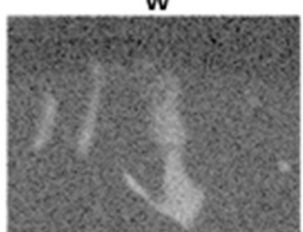

Figure 3: BSI and EDX elemental maps of MarM 509 after exposure at $700{ }^{\circ} \mathrm{C}$ for 100 hours in air. 
Figure 4 shows a BSI and associated elemental maps of Rene 80 after 100 hours of exposure to air at $700{ }^{\circ} \mathrm{C}$. In contrast to MarM 509, the metal carbide precipitate has not been vulnerable to rapid oxidation and remains relatively unaffected by this exposure.

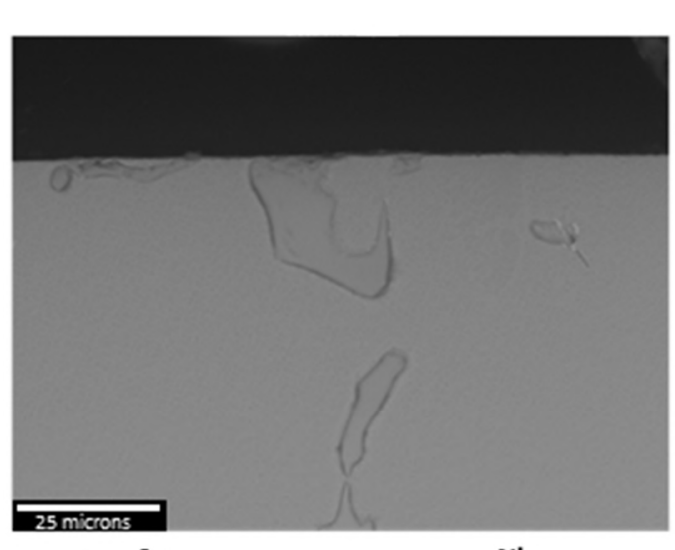

Co

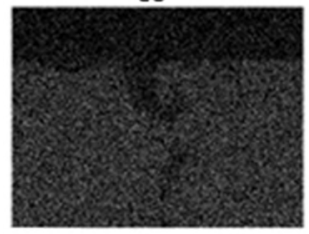

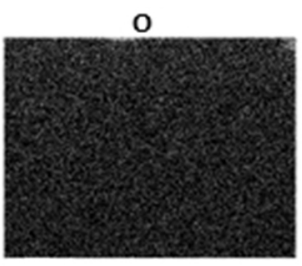

Ti

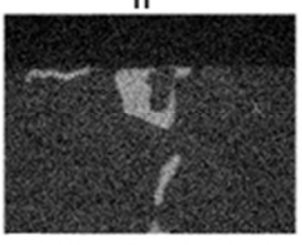

Mo
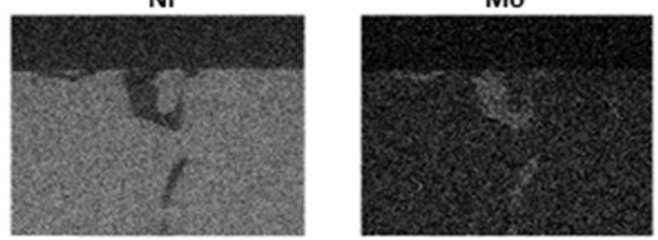

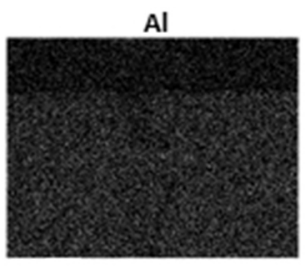

$\mathrm{Cr}$

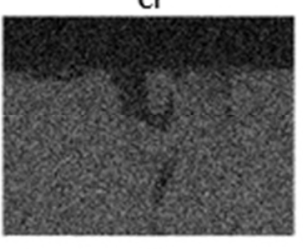

W

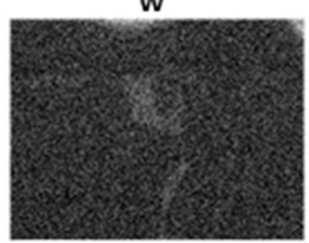

Figure 4: BSI and EDX elemental maps of Rene 80 after exposure at $700{ }^{\circ} \mathrm{C}$ for 100 hours in air

Figure 5 shows selected BSI and associated elemental maps for MarM 509 after exposure for 100 hours at $700{ }^{\circ} \mathrm{C}$ to an atmosphere of $90 \mathrm{ppm} \mathrm{SO}, 10.5 \% \mathrm{CO}_{2}, 8.5 \%$ $\mathrm{O}_{2}$ and $5 \% \mathrm{H}_{2} \mathrm{O}$ balanced in $\mathrm{N}_{2}$ and deposit flux of $1.5 \mu \mathrm{g} / \mathrm{cm}^{2} / \mathrm{h}$ of $80 / 20(\mathrm{Na} / \mathrm{K})_{2} \mathrm{SO}_{4}$. The precipitate bisecting the surface has fully oxidized and new phases have formed in the alloy adjacent to the alloy/precipitate phase boundary. The EDX maps show these phases to be rich in sulphur (as such they may be sulphide precipitates); a feature more commonly associated with type I hot corrosion. Internal sulphidation has also occurred below the surface scale on the bulk alloy, although only to a depth of approximately 5 $\mu \mathrm{m}$ compared to $15 \mu \mathrm{m}$ when adjacent to the precipitate. The presence of deeper 
sulphur species close to the phase boundary suggests that the corrosive species are able to use this phase boundary to transport more rapidly into the alloy.

The light, Ta-rich and $\mathrm{W}$ - rich surface precipitate in Figure 5 extends down to a two phase region rich in chromium (of the type shown in Figure 2 (a) point 3 ). The carbide species within this zone have oxidized laterally from the point where this dark Cr-rich carbide meets the tantalum carbide phase bisecting the surface. This again shows how precipitates can allow the transport of deleterious species deeper into the alloy matrix than precipitate free regions.

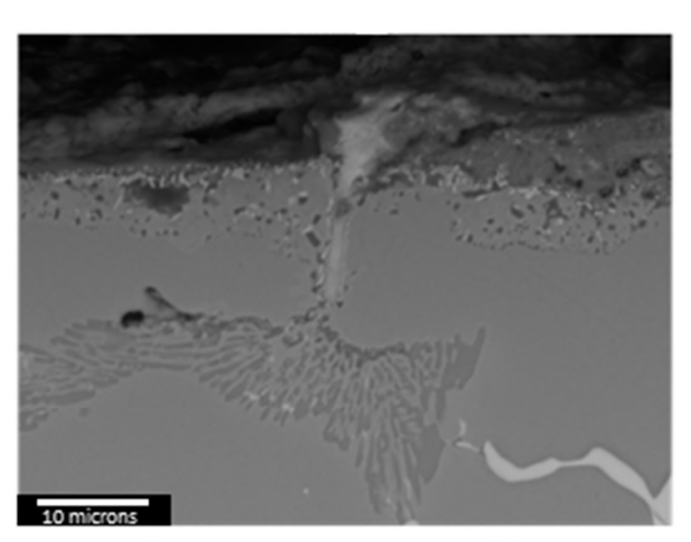

Co

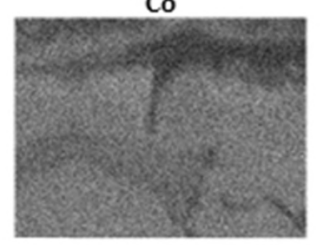

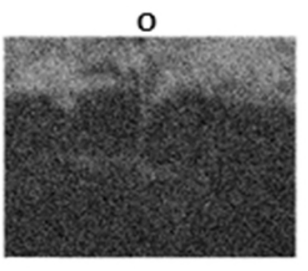

$\mathrm{Ti}$

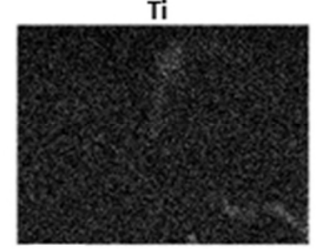

Ta
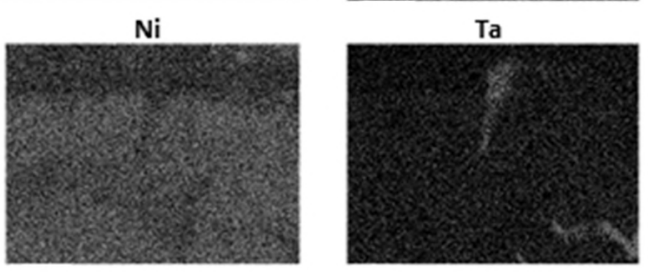
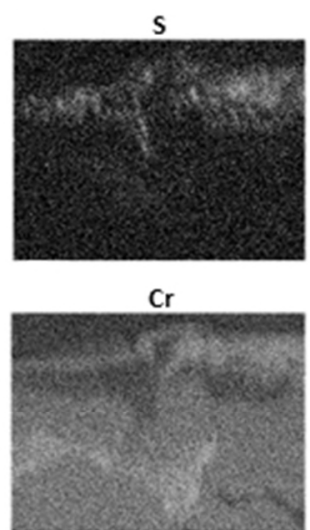

W

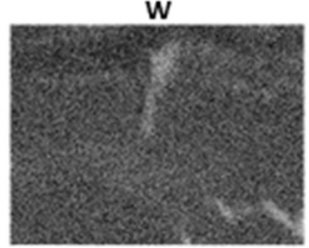

Figure 5: BSI and EDX elemental maps of MarM 509 after exposure at $700{ }^{\circ} \mathrm{C}$ to an atmosphere of 90 ppm $\mathrm{SO}_{\mathrm{x}}, 10.5 \% \mathrm{CO}_{2}, 8.5 \% \mathrm{O}_{2}$ and $5 \% \mathrm{H}_{2} \mathrm{O}$ balanced in $\mathrm{N}_{2}$ and deposit flux of $1.5 \mu \mathrm{g} / \mathrm{cm}^{2} / \mathrm{h}$ of $80 / 20(\mathrm{Na} / \mathrm{K})_{2} \mathrm{SO}_{4}$ for 100 hours.

Figure 6 shows an example BSI typical of the corrosion front of MarM 509 after exposure for 500 hours at $700{ }^{\circ} \mathrm{C}$ to an atmosphere of $90 \mathrm{ppm} \mathrm{SO}_{\mathrm{x}}, 10.5 \% \mathrm{CO}_{2}, 8.5 \%$ $\mathrm{O}_{2}$ and $5 \% \mathrm{H}_{2} \mathrm{O}$ balanced in $\mathrm{N}_{2}$ and deposit flux of $1.5 \mu \mathrm{g} / \mathrm{cm}^{2} / \mathrm{h}$ of $4 / 1(\mathrm{Na} / \mathrm{K})_{2} \mathrm{SO}_{4}$. This longer exposure to type II hot corrosion conditions has led to the formation of a thick corrosion product scale. The remains of the carbide precipitates are still visible 
within this corrosion product and internal sulphur-rich precipitates have formed close to the metal surface. Where the carbide precipitates meet the surface the ingress of oxygen appears to reach deeper along the precipitates than the sulphur species in the areas adjacent to them which, in turn, extend deeper than the general sulphide front. This is consistent across the whole sample with the possible exceptions of locations where chromium-rich carbide phases are present and the rates of internal oxidation and sulphidation may be different.

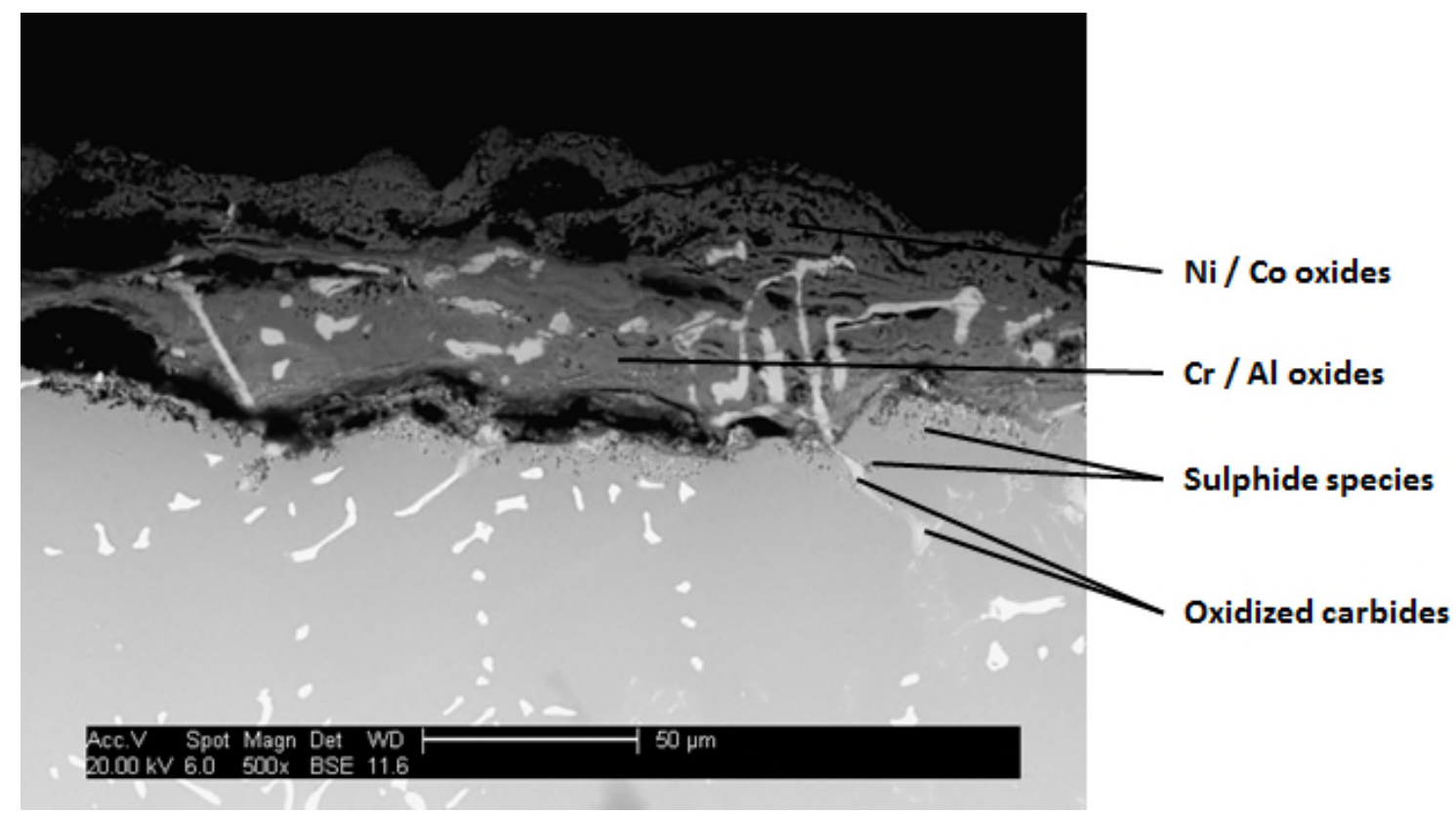

Figure 6: BSI of MarM 509 after exposure at $700{ }^{\circ} \mathrm{C}$ to an atmosphere of $90 \mathrm{ppm} \mathrm{SO}_{\mathrm{x}}$, $10.5 \% \mathrm{CO}_{2}, 8.5 \% \mathrm{O}_{2}$ and $5 \% \mathrm{H}_{2} \mathrm{O}$ balanced in $\mathrm{N}_{2}$ and deposit flux of $1.5 \mu \mathrm{g} / \mathrm{cm}^{2} / \mathrm{h}$ of $80 / 20(\mathrm{Na} / \mathrm{K})_{2} \mathrm{SO}_{4}$ for 500 hours. Micrograph shows the propagation stage of a mixed mode hot corrosion mechanism.

Figure 7 shows an example BSI and associated elemental maps of Rene 80 after 100 hours of exposure at $700{ }^{\circ} \mathrm{C}$ to 90 ppm $\mathrm{SO}_{x}, 10.5 \% \mathrm{CO}_{2}, 8.5 \% \mathrm{O}_{2}$ and $5 \% \mathrm{H}_{2} \mathrm{O}$ balanced in $\mathrm{N}_{2}$ and deposit flux of $1.5 \mu \mathrm{g} / \mathrm{cm}^{2} / \mathrm{h}$ of $80 / 20(\mathrm{Na} / \mathrm{K})_{2} \mathrm{SO}_{4}$. The degradation shown in this micrograph has some typical type II hot corrosion features: e.g. a form of (in this case broad) pit with a layered external corrosion product based on the alloy 
elements' affinities for oxygen. The BSI also indicates some internal sulphidation close to the alloy surface (to a depth of approximately $2 \mu \mathrm{m}$ ) at the extremes of the image, albeit to a much lesser extent than that shown in Figure 5 for MarM 509 (approximately $5 \mu \mathrm{m})$. Rene 80 is a molybdenum containing alloy, with that element being shown in Figure 2 to preferentially partition to the precipitate phases. Due to an overlap of X-ray energy peaks, molybdenum and sulphur can be difficult to differentiate in these EDX maps. In this case there appears to be some sulphur containing precipitates in the alloy adjacent to the carbide precipitate visible on the micrograph, but again to a lesser extent than the MarM 509 carbide precipitate shown in Figure 5. The metal carbide precipitate itself appears to have partially oxidized, with the lower region remaining unreacted.

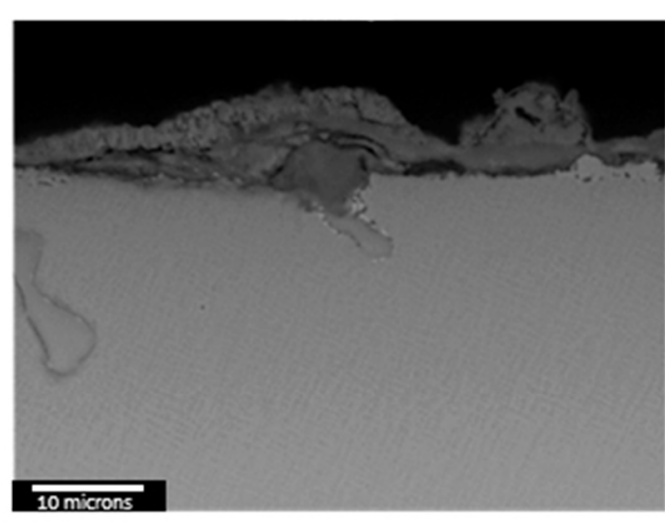

Co

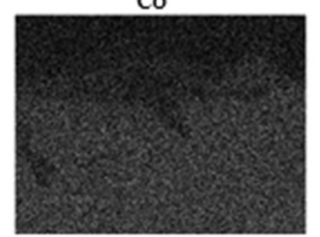

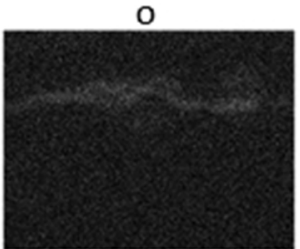

Ti

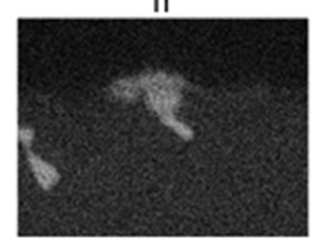

$\mathrm{Mo} / \mathrm{S}$

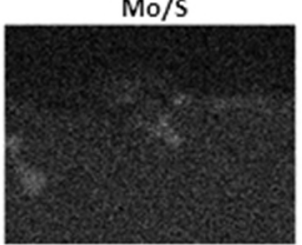

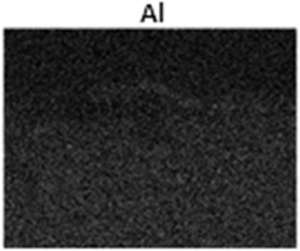

$\mathrm{Cr}$

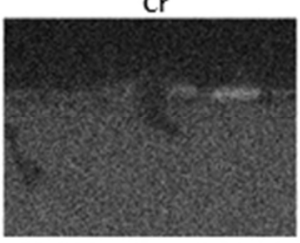

W

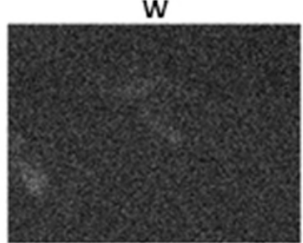

Figure 7: BSI and EDX elemental maps of Rene 80 after exposure at $700{ }^{\circ} \mathrm{C}$ to an atmosphere of 90 ppm $\mathrm{SO}_{\mathrm{x}}, 10.5 \% \mathrm{CO}_{2}, 8.5 \% \mathrm{O}_{2}$ and $5 \% \mathrm{H}_{2} \mathrm{O}$ balanced in $\mathrm{N}_{2}$ and deposit flux of $1.5 \mu \mathrm{g} / \mathrm{cm}^{2} / \mathrm{h}$ of $80 / 20(\mathrm{Na} / \mathrm{K})_{2} \mathrm{SO}_{4}$ for 100 hours.

In environments that can cause both oxidation and type II hot corrosion, the carbide precipitates located close to the surface (and possibly intersecting it out of the imaging plane) of MarM 509 have been more aggressively attacked by the environment, 
leading to localised alloy degradation. The alloy surface suffers less attack when the areas close by contain no carbide precipitates. In the corrosive environment, the carbide precipitates have acted as a nucleation point for the propagation stage of type II hot corrosion, having reduced or negated the incubation period for this damage mechanism. The kinetics for this carbide phase attack appear to be more rapid for MarM 509 than Rene 80 , which could be attributed to the inability of MarM 509 to develop a protective scale on surfaces close to carbide precipitates. In addition, MarM 509 has a much greater frequency of carbide precipitates distributed throughout the alloy matrix. These factors are likely to contribute to the relatively poor type II hot corrosion performance of this alloy in other studies [14] and should be considered in the development of type II hot corrosion kinetic models.

\section{Conclusions}

Oxidation and type II hot corrosion exposures have been carried out for up to 500 hours at $700{ }^{\circ} \mathrm{C}$ for example nickel-based and cobalt-based alloys (Rene 80 and MarM 509 respectively). Metal carbide precipitates in these alloys have been shown to detrimentally affect their environmental resistance by disrupting the formation of protective surface oxides. This shortens, or possibly, as in the case of MarM 509, negates the incubation period for type II hot corrosion at localized points on the metal surface.

During both oxidation and the incubation period of type II hot corrosion, the near surface metal carbide precipitates disrupt the formation of continuous protective oxides and allow inward transport and hence oxidation of these carbides. Transport of reactive species via the originally carbide phases provides pathways for rapid movement of these elements into the alloys and allows the alloy to be further attacked in adjacent regions. 


\section{Acknowledgements}

The sample exposures reported in this paper were supported by the European Union Framework 7 programme through Grant number FP7-239349 (H2-IGCC).

\section{References}

[1] H. Oskarsson, Material Challenges in Industrial Gas Turbines, Iron Steel Int, 2007, vol. 14, no. 5 SUPPL. 1, pp. 11-14.

[2] T. M. Pollock and S. Tin, Nickel-Based Superalloys for Advanced Turbine Engines: Chemistry, Microstructure, and Properties, J. Propuls. Power, vol. 22, no. 2, pp. 361-374, 2006.

[3] R. C. Reed, The Superalloys: Fundamentals and Applications. Cambridge University Press, 2006.

[4] B. Bordenet, High Temperature Corrosion in Gas Turbines: Thermodynamic Modelling and Experimental Results (thesis), Rheinisch-Westfälische Institute of Technology, 2004.

[5] A. Potter, J. Sumner, N. J. Simms, and J. E. Oakey, Hot corrosion in the next generation of industrial gas turbines, Proceedings of Eurocorr 2014, Piza, 2014.

[6] R. A. Rapp, J. H. Devan, D. L. Douglass, P. C. Nordine, F. S. Pettit, and D. P. Whittle, High temperature corrosion in energy systems, Mater. Sci. Eng., vol. 50, no. 1, pp. $1-17,1981$.

[7] A. S. Khanna, Introduction to high temperature oxidation and corrosion. Materials Park, OH: ASM International, 2002.

[8] J. R. Nicholls and N. J. Simms, Gas Turbine Oxidation and Corrosion, in Shreir's Corrosion, T. J. A. Richardson, Ed. Oxford: Elsevier, 2010, pp. 518-540.

[9] N. Birks, G. H. Meier, and F. S. Pettit, Introduction to the high-temperature oxidation of metals, vol. 2. Cambridge, UK: Cambridge University Press, 2006. 
[10] F. Pettit, Hot Corrosion of Metals and Alloys, Oxid. Met., vol. 76, no. 1-2, pp. 1$21,2011$.

[11] J. R. Nicholls, N. J. Simms, and A. Encinas-Oropesa, Modelling hot corrosion in industrial gas turbines, Mater. High Temp., vol. 24, no. 3, pp. 149-162, 2007.

[12] J. Sumner, A. Encinas-Oropesa, N. J. Simms, and J. R. Nicholls, Type II Corrosion: Kinetics Studies of CMSX-4, Oxid. Met., vol. 80, no. 5-6, pp. 553$563,2013$.

[13] V. Biss, Phase Analysis of Standard and Molybdenum-Modified Mar-M509 Superalloys, J. Test. Eval., vol. 5, no. 3, pp. 217-223, 1977.

[14] J. Sumner, A. Potter, N. J. Simms, and J. E. Oakey, Hot corrosion resistance of gas turbine materials in combusted syngas environments, Mater. High Temp., vol. 32, no. 1-2, pp. 177-187, 2015. 